\title{
Residents from non-English speaking countries of birth in Australian aged care facilities
}

\author{
$\longrightarrow$ \\ - \\ 1 \\ Lee-Fay Low* \\ Faculty of Health Sciences, University of Sydney, NSW, Australia \\ Dina LoGiudice \\ Department of Aged Care, Royal Melbourne Hospital, Melbourne, Victoria, Australia \\ *corresponding author, Faculty of Health Sciences, 75 East St Lidcombe 2141, NSW, Australia. \\ Email:lee-fay.low@sydney.edu.au, phone: +61 290367368
}

Acknowledgements: A/Prof Low is funded by an NHMRC Career Development Fellowship. Our thanks to lan Appleby and his team at the Australian Institute of Health and Welfare for providing these data.

Conflicts of interest: The authors have no conflicts of interest

Running head: Non-English speaking residents in aged care

This is the author manuscript accepted for publication and has undergone full peer review but has not been through the copyediting, typesetting, pagination and proofreading process, which may lead to differences between this version and the Version of Record. Please cite this article as doi: 10.1111/ajag.12527

This article is protected by copyright. All rights reserved 


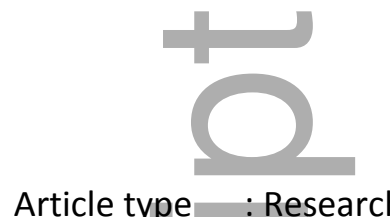

Article type : Research

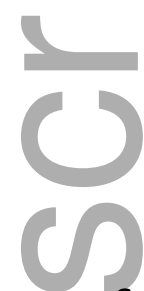

\title{
Residents from non-English speaking countries of birth in Australian aged care facilities
}

\author{
Abstract \\ Objectives: To describe activity of daily living, behavioural and complex care needs of residents \\ born in non-English speaking countries in Australian aged care facilities, .
}

Methods: De-identified cross-sectional data were provided by the Australian Institute of Health and Welfare for all residents in government funded facilities at 30 June 2015. Analyses included t-tests, chi-squared tests and logistic regressions.

Results: 33168 (19\%) of residents were born in one of 188 non-English speaking countries. Compared to residents born in English speaking countries, they were significantly younger, lived in larger facilities, were more likely to be male and live in an urban area. Their care requirements were greater for activities of daily living, behavioural and complex care. Residents 
from non-English speaking countries living in ethno-specific facilities had higher levels of these needs.

Conclusion: The needs of residents born in non-English speaking countries should be considered when planning aged care services.

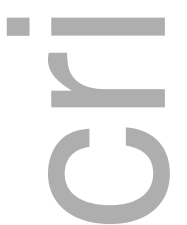

In 2011, almost $20 \%$ of Australians aged over 50 were born in a non-English speaking country. In 2012-13, three in 10 aged care clients (i.e. about 70,000) were born overseas (1). There is considerable variation in the use of aged care services by type of service (home vs residential care) and region of birth. For those living in Australia, people born in Australia utilize the highest rate of aged care services, followed by those born in northwest Europe and UK/Ireland, with lowest rates of use by those born in Northeast and South-east Asia People born in Australia use residential care at more than twice the rate than those born in Southeast Asia and Northeast Asia (1). The international literature also suggests differential rates of use of residential aged care by racial and ethnic minorities - such as low utilization of residential aged care by Hispanics in the USA $(2,3)$. The reasons for the low use of residential aged care are many, including a combination of reluctance to use this kind of service for cultural reasons, difficulty accessing services, and inability to access culturally appropriate services (4). For example the value of 'filial piety' in Chinese culture sees use of residential care services as a last resort when families are not able to fulfill their duty of care (5). Hence, low rates of use may reflect delayed entry to care, despite relatively high care needs of migrants compared to Australian born residents.

Residential aged care facilities can be described as ethno-specific (i.e. catering for people from a specific non-Australian cultural background, or country of birth), multicultural (i.e. catering generally for residents from culturally and linguistically diverse backgrounds) or mainstream (i.e. not catering specifically for culturally and linguistically diverse backgrounds). There are no 
Australian data on the number of ethno-specific aged care facilities in Australia. Italians and Chinese living in Australian ethno-specific facilities are observed to communicate more frequently with staff, and are prescribed lower rates of anti-psychotic medications compared to Italians and Chinese in mainstream facilities $(6,7)$. Families of Greeks and Italians living in in Australian ethno-specific facility were more satisfied with their care than those living in mainstream facilities (8). Residents in mainstream facilities from non-English speaking backgrounds may receive less person-centred care than native English speakers - a survey of Victorian facilities found that one quarter of facilities did not use any specific service for residents who spoke non-English languages, and that most residents did not have access to staff who spoke their language (9).

It has been proposed that behavioural and psychological symptoms in dementia occur as a response to unmet needs (10). Mainstream facilities may find it more difficult to meet the needs of residents from non-English speaking backgrounds, hence behavioural symptoms may be higher in people from non-English speaking backgrounds living in mainstream facilities. However a small study of Chinese in Australian ethno-specific nursing homes $(n=42)$ showed they had similar rates of behavioural symptoms of dementia with residents from English speaking backgrounds in mainstream facilities $(n=51)(11)$. We could locate no research on whether multicultural residential aged care facilities better meet the care needs of residents from non-English speaking backgrounds than mainstream facilities.

The aim of this paper is to describe residents born in non-English speaking countries compared to those born in English speaking countries in Australian residential aged care facilities, including their care needs as described using the aged care funding instrument (ACFI).

We hypothesise that

1) Residents from non-English speaking backgrounds will have higher activity of daily living and complex care needs compared to those from English-speaking backgrounds 
2) Residents from non-English speaking backgrounds will have higher levels of behavioural care needs compared to those from English-speaking backgrounds

3) Residents from non-English speaking backgrounds in ethno-specific nursing homes will have similar levels of behavior needs to English speaking residents in mainstream facilities.

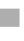

\section{Methods}

The University of Sydney human ethics committee confirmed that we did not require ethical approval for this study as the project is considered negligible risk research, involved the use of existing records that contain only non-identifiable data.

\section{Data}

De-identified cross-sectional data were provided by the Australian Institute of Health and Welfare for all aged care residents in Australian government funded facilities at 30 June 2015. The data set included: age, gender, country of birth, indigenous status, aged care funding instrument (ACFI) activity of daily living (ADL), ACFI behavioural care needs and ACFI complex care needs scores, and randomly generated provider ID.

The ACFI is the instrument used to obtain Australian federal government funding for residents and is completed by residential aged care facility staff when residents are admitted and as care needs change. Care needs for ADL, behavior and complex care are each scored as $0=$ nil, $1=$ low, 2 = medium and 3 = high, more funding is allocated for higher needs. The ACFI ADL score is based on items on nutrition, mobility, personal hygiene, and toileting (each rated as independent, requiring supervision or requiring physical assistance), and continence (rated on frequency of incontinence). The ACFI behavioural care needs score is based on items for cognitive skills and depression (rated as none, mild, moderate or severe), and wandering, verbal behavior (i.e. verbal refusal of care, verbal disruption, paranoid ideation that disrupts others or verbal sexually inappropriate advances - rated on frequency) and physical behaviour (i.e. threatening behavior that has the potential to be harmful, socially inappropriate behavior that impacts on other residents, being constantly physically agitated - rated on frequency). The 
ACFI complex care needs score is based on items on medication (rated on complexity, frequency and assessment time) and complex health care procedures (rated on complexity and frequency) (12).

English speaking countries were based on the grouping previously used by the Australian Bureau of Statistics and comprised Australia, Canada, Republic of Ireland, New Zealand, South Africa, England, Scotland, Wales, Northern Ireland, United States of America (13)

There are no formal criteria for defining ethno-specific facilities or multicultural facilities. Multicultural facilities were defined as those where $70 \%$ or more residents were born in nonEnglish speaking countries. Ethno-specific facilities defined as were a subset of multicultural facilities where $70 \%$ or more residents were born in the same non-English speaking country (i.e. $>70 \%$ residents born in Italy, or $>70 \%$ residents born in China).

\section{Analyses}
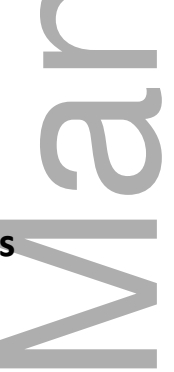

The following tests were used to examine demographic differences between residents born in English-speaking and non-English speaking countries: $\mathrm{t}-\mathrm{t}$ test for continuous data and chisquared tests for categorical data. To address hypotheses one and two, logistic regressions were undertaken to examine the relationship between English and non-English speaking countries of birth and levels of care needs after controlling for covariates (age, gender, remoteness and facility size). To address hypothesis three chi-squared tests were undertaken to test the differences on care needs between residents born in non-English speaking countries living in multicultural facilities, and residents born in English-speaking countries living in nonmulticultural facilities; and residents born in the dominant country of birth of ethno-specific facilities compared to residents born in English-speaking countries living in non-ethno-specific facilities. We have calculated effect sizes to help describe the magnitude of the differences 
between groups. We have applied the following interpretations to effect sizes - Cohen's d small 0.2 , medium 0.5, large $=0.8, r$ or Cramer's $\vee$ small $=0.1$, medium $=0.3$, large $=0.5(14)$.

\section{$\underline{\text { Results }}$}

\section{Care needs of residents born in non-English speaking countries}

There were 172,798 residents in permanent aged care as at 30 June 2015 . Of these, 54,611 $(31.6 \%)$ were men and 118,187 (68.42\%) were women. Their average age was $84.6 \pm 9.1$ years and ranged between 20 and 115 years. Residents lived in 2679 facilities with an average of 64.5 \pm 36.5 beds (range 1 to 317 ).

Country of birth data are shown in table 1 . Australia was the most common country of birth followed by England and Italy, and country of birth data were unavailable for 774 residents. There were 1478 people who identified as being from Aboriginal or Torres Strait descent, of these 1249 (96.7\%) were born in Australia with the remainder born across a wide range of countries. All residents identified as Aboriginal or Torres Strait were excluded from further analyses, as culturally they are different from those from English-speaking backgrounds it was beyond the scope of this paper to articulate and explore their care needs.

Nineteen percent of residents $(n=33,468$ ) were born in non-English speaking countries (see table 2), from 188 different countries of birth. Compared to those born in English speaking countries, people born in non-English speaking countries were significantly younger more likely to be male, live in more urban areas and on average lived in larger aged care facilities. Residents born in non-English speaking countries had significantly higher activity of daily living, behavioural and complex care needs. All differences were small effects.

Ordinal logistic regressions found higher levels of activity of daily living, behavioural and complex care needs remained in residents born in non-English speaking countries after controlling for age, gender, remoteness and facility size (see table 3).

\section{Ethno-specific and mainstream facilities}


The number of residents born in non-English speaking countries ranged from 0 to 197, the mean was $12.5 \pm 16$.9. The proportion of residents born in non-English speaking countries ranged from $0 \%$ to $100 \%$, the mean was $18.4 \% \pm 19.6$.

For the 18,217 residents born in the top 10 non-English speaking countries of birth, between $0 \%$ to $100 \%$ of their co-residents were born in the same country of birth (the median was 5.00 , and mean was 19.32, SD = 27.23).

There were 108 multicultural facilities where over $70 \%$ of residents were born in non-English speaking countries. Of these, 39 were ethno-specific with over $70 \%$ of residents from one nonEnglish speaking country of birth. The number of ethno-specific facilities for the top 10 nonEnglish speaking countries of birth are shown in table 4.

Residents born in non-English speaking countries living in multicultural facilities had higher reported levels of ACFI activity of daily living, behavior and complex care needs compared to residents born in English speaking countries (see table 5). Similarly, residents born in nonEnglish countries living in ethno-specific facilities congruent with their country of birth, had higher levels of activity of daily living, behavior and complex care needs compared to residents born in English speaking countries in mainstream facilities. These effect sizes were small.

\section{Discussion}

Our findings confirmed hypotheses one and two - residents from non-English speaking backgrounds had slightly higher care requirements for activity of daily living, behavior and complex care needs compared to residents born in English speaking countries. Although we have no data to support these differences, previous researchers have suggested that people born in nonEnglish speaking countries may have higher care needs when in aged care facilities because they are reluctant to or have difficulty accessing residential aged care, and therefore enter care later in the progression of disease or frailty (4). This is reflected in average higher care needs than those from English speaking backgrounds.

This article is protected by copyright. All rights reserved 
Contrary to hypothesis three, residents born in non-English speaking countries in ethno-specific facilities had higher levels of behavioural needs than residents born in English speaking countries in mainstream facilities. According to the theory of unmet needs, behavioural symptoms in dementia are an expression of distress or discomfort due to unmet needs. We hypothesized that multicultural or ethno-specific facilities would be better able to understand and meet the needs of residents from non-English speaking backgrounds, resulting in lower levels of behavioural care needs. However the assumed culturally and language-appropriate care provided by multicultural or ethno-specific facilities is not associated with lower levels of behavioural care needs of residents. This may be because behavioural needs are higher on entering the facility, consistent with their higher levels of ADL and complex care needs. Alternatively it may be because ethno-specific care does not result in a reduction in behavioural symptoms.

There was variability in the number of ethno-specific facilities available for specific countries of birth. This may reflect the migration history from various countries, the geographical clustering of migrants from that country or the extent of differences between that culture and mainstream Australian culture. Well-established geographically densely located migrant communities may be more likely to be able to resource an ethno-specific facility. Cultures more similar to English-speaking countries may perceive less need for ethno-specific facilities. The demographic profile of Australians are changing (15) with the majority of recent migrants coming from China rather than Europe, the needs of these communities needs to be considered in planning residential care.

This study is limited by the characteristics of the dataset. Only country of birth was available to characterise residents - languages spoken and ethnicity were not taken into account. The ACFI data only had four levels so there was not much variation in care needs. Further, care need data may have been biased if ACFI assessors wanted to maximize scores in order to maximize facility income (16). There were only a few demographic and other variables available to include in these analyses. We did not have formal descriptions of whether facilities were ethno-specific or multicultural and made assumptions in our classifications into these categories. We excluded 
people from Aboriginal and Torres Strait Islander backgrounds, these results do not apply to them. Study strengths are that we had all data for all Australian aged care residents, and were able to examine the influence of some facility-level characteristics.

In conclusion, $19 \%$ of Australian aged care residents are born in a wide number of non-English speaking countries. They have higher behavioural and complex care needs, even when living in multicultural or ethno-specific facilities. This challenges the assumption that culturally-specific care is better able to meet the behavioural care needs of residents from non-English countries. Aged care policy makers should consider these factors when planning services (particularly access), quality improvement and policy standards.

Policy impact statement (50 words): This paper highlights the high proportion, diversity of backgrounds and higher care needs of people from non-English speaking countries in Australian residential aged care. Access to residential care and provision of culturally appropriate care should be considered as part of policy development.

Practice impact statement (50 words): All residential aged care providers should be aware that people born in non-English speaking countries have higher care functional, behavioural and complex care needs. It is unclear whether multicultural or ethno-specific care better meets the needs of people from non-English backgrounds than mainstream care.

\section{References}

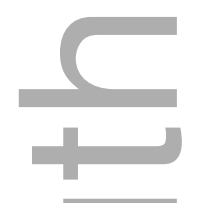

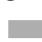

1. Australian Institute of Health and Welfare (AIHW). Residential aged care and aged care packages in the community 2012-13 Canberra: Australian Institute of Health and Welfare 2014 [Available from: http://www.aihw.gov.au/aged-care/residential-and-community-2012-13/\#toc. 
2. Thomeer MB, Mudrazija S, Angel JL. How do race and hispanic ethnicity affect nursing home admission? Evidence from the health and retirement study. Journals of Gerontology - Series B Psychological Sciences and Social Sciences. 2015;70(4):628-38.

3. Feng Z, Fennell ML, Tyler DA, Clark M, Mor V. Growth of racial and ethnic minorities in us nursing homes driven by demographics and possible disparities in options. Health Aff (Millwood). 2011;30(7):1358-65.

4. Cheng A, Cruysmans B, Draper B, Hayward-Wright N, Jeon Y-H, Logiudice D, et al. Strategic Directions in CALD Dementia Research in Australia. Sydney: Dementia Collaborative Research Centre, University of New South Wales; 2009.

5. Chow N. The practice of filial piety and its impact on long-term care policies for elderly people in Asian Chinese communities2006.

6. Runci SJ, Eppingstall BJ, O'Connor DW. A comparison of verbal communication and psychiatric medication use by Greek and Italian residents with dementia in Australian ethno-specific and mainstream aged care facilities. Int Psychogeriatr. 2012;24(5):733-41.

7. Goh I, Low LF, Brodaty H. Levels and rates of depression among Chinese people living in Chinese ethno-specific and mainstream residential care in Sydney. Int Psychogeriatr. 2010;22(2):237-45.

8. Runci SJ, Eppingstall BJ, Van Der Ploeg ES, O'Connor DW. Comparison of family satisfaction in Australian ethno-specific and mainstream aged care facilities. J Gerontol Nurs. 2014;40(4):54-63.

9. Runci SJ, Eppingstall BJ, van der Ploeg ES, Graham G, O'Connor DW. The language needs of residents from linguistically diverse backgrounds in Victorian aged care facilities. Australasian Journal on Ageing. 2015;34(3):195-8.

10. Kolanowski AM. An overview of the need-driven dementia-compromised behavior model. J Gerontol Nurs. 1999;25(9):7-9.

11. Wu HZY, Low L-F, Xiao S, Brodaty H. A pilot study of differences in behavioral and psychological symptoms of dementia in nursing home residents in Sydney and Shanghai. Int Psychogeriatr. 2009;21(03):476-84.

12. Australian Government Department of Health and Ageing. Aged Care Funding Instrument User Guide. Canberra: Commonwealth Government of Australia; 2007.

13. Australian Bureau of Statistics. 3417.0 - Understanding Migrant Outcomes - Enhancing the Value of Census Data, Australia, 2011 Canberra2013 [updated 19/09/2013. Available from: http://www.abs.gov.au/Ausstats/abs@.nsf/Latestproducts/3417.0Glossary12011?opendocument\&tabn ame=Notes $\&$ prodno $=3417.0 \&$ issue $=2011 \&$ num $=\&$ view .

This article is protected by copyright. All rights reserved 
14. Cohen J. Statistical power for the behavioral sciences. 2nd ed. Hillsdale, New Jersey: Lawrence Erlbaum Associates, Publishers; 1988.

15. Australian Bureau of Statistics. 2071.0 - Census of Population and Housing: Reflecting Australia Stories from the Census, 2016 Canberra: Australian Bureau of Statistics; 2017.

16. McNamee J, Poulos C, Seraji H, Kobel C, Duncan C, Westera A, et al. Alternative Aged Care Assessment, Classification System and Funding Models Final Report. Wollongong: Centre for Health Service Development, Australian Health Services Research Institute, University of Wollongong; 2017.

Table 1. Countries of birth of Australian aged care residents

\begin{tabular}{|c|c|c|}
\hline Country & Frequency & Percentage \\
\hline \multicolumn{3}{|l|}{ Australia } \\
\hline Indigenous & 1478 & 0.9 \\
\hline Non-indigenous & 118447 & 68.5 \\
\hline not born in Australia & 52097 & 30.1 \\
\hline Missing data on country of birth & 774 & 0.4 \\
\hline \multicolumn{3}{|c|}{ Most common countries of birth outside Australia: } \\
\hline England & 13225 & 7.7 \\
\hline Italy & 5814 & 3.4 \\
\hline Scotland & 2562 & 1.5 \\
\hline Germany & 2425 & 1.4 \\
\hline Greece & 2317 & 1.3 \\
\hline Netherlands & 2017 & 1.2 \\
\hline New Zealand & 1742 & 1.0 \\
\hline Poland & 1622 & 0.9 \\
\hline China (excludes SARs and Taiwan) & 1434 & 0.8 \\
\hline Ireland & 1027 & 0.6 \\
\hline India & 1024 & 0.6 \\
\hline
\end{tabular}

This article is protected by copyright. All rights reserved 


\begin{tabular}{lrr} 
Croatia & 986 & 0.6 \\
Malta & 904 & 0.5 \\
Hungary & 801 & 0.5 \\
\hline & & \\
Born in English speaking country & 137852 & 79.8 \\
Born in non-English speaking country & 33468 & 19.4
\end{tabular}

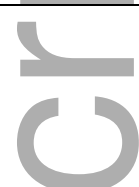

Table 2. Comparison between residents born in English-speaking and non-English speaking countries
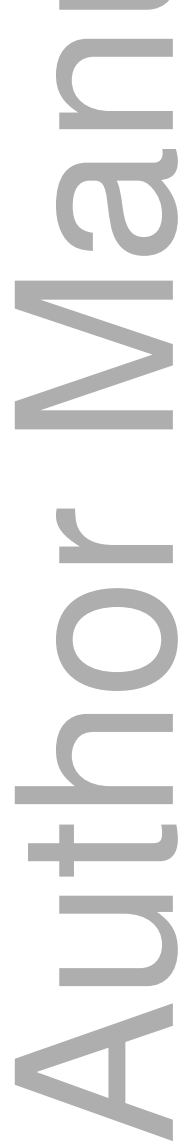

This article is protected by copyright. All rights reserved 


\begin{tabular}{|c|c|c|c|}
\hline & $\begin{array}{l}\text { English speaking } \\
\text { country ( } n= \\
137852)\end{array}$ & $\begin{array}{l}\text { Non-English } \\
\text { speaking country (n } \\
=33468 \text { ) }\end{array}$ & $\begin{array}{l}\text { Stats (English vs non- } \\
\text { English speaking) }\end{array}$ \\
\hline Age (mean, SD) & $84.69 \pm 9.22$ & $84.59 \pm 8.214$ & $\begin{array}{l}t=-0.074, p=0.038 \\
\text { Cohen's } d=0.126\end{array}$ \\
\hline Gender - Female & $95426(69.2 \%)$ & 21908 (64.5\%) & $x^{2}=176.782, p<$ \\
\hline Male & $42426(30.8 \%)$ & $11560(35.5 \%)$ & 0.001 \\
\hline & & & Phi $=-0.032$ \\
\hline ADL & & & $x^{2}=342.34, p<0.001$ \\
\hline Nil & 1414 (1.0\%) & 291 (0.9\%) & Phi $=0.045$ \\
\hline Low & $25426(17.9 \%)$ & $5949(14.9 \%)$ & \\
\hline Medium & $42320(30.9 \%)$ & $9498(28.6 \%)$ & \\
\hline High & $68693(50.2 \%)$ & $18453(55.6 \%)$ & \\
\hline Behaviour ne & & & $x^{2}=1606.045, p<$ \\
\hline Nil & $8458(5.2 \%)$ & $935(2.8 \%)$ & 0.001 \\
\hline Low & $18560(11.3 \%)$ & $2957(8.9 \%)$ & Cramer's V = 0.0097 \\
\hline Medium & $31688(19.3 \%)$ & $6785(20.4 \%)$ & \\
\hline High & $78247(57.1 \%)$ & $22524(67.8 \%)$ & \\
\hline Complex care needs & & & $x^{2}=274.251, p<$ \\
\hline Nil & $5999(4.3 \%)$ & 1167 (3.5\%) & 0.001, \\
\hline Low & $25360(18.5 \%)$ & 5357 (16.1\%) & Cramer's V = 0.040 \\
\hline Medium & $36113(26.4 \%)$ & $8244(24.8 \%)$ & \\
\hline High & $69481(50.7 \%)$ & $18433(55.5 \%)$ & \\
\hline $\begin{array}{l}\text { Number of residents in } \\
\text { facility (mean, SD) }\end{array}$ & $84.79 \pm 40.78$ & $87.92 \pm 43.38$ & $\begin{array}{l}t=-11.974, p<0.001, \\
\text { Cohen's } d=0.0743\end{array}$ \\
\hline $\begin{array}{l}\text { Beds per } 100065+\text { in the } \\
\text { Aged Care Planning Region }\end{array}$ & $55.19 \pm 7.92$ & $56.81 \pm 7.55$ & $\begin{array}{l}t=-34.00, p<0.001 \\
\text { Cohen's } d=0.209\end{array}$ \\
\hline$\%$ persons from non- & $14.55 \pm 12.41$ & $39.57 \pm 29.53$ & $t=-239.31 m p<$ \\
\hline English speaking countries & & & 0.001, Cohen's d = \\
\hline
\end{tabular}

This article is protected by copyright. All rights reserved 


\begin{tabular}{llll}
\hline $\begin{array}{l}\text { s in facility } \\
\text { Remoteness }\end{array}$ & & & 1.104426 \\
Major Cities & $58.4(58.7 \%)$ & $29341(87.7 \%)$ & $\mathrm{X}^{2}=6240.01, \mathrm{p}<$ \\
$\quad$ Inner regional & $34454(25.0 \%)$ & $2861(8.5 \%)$ & 0.001, \\
$\quad$ Outer Regional & $12181(8.8 \%)$ & $1172(3.5 \%)$ & Cramer's V = 0.191 \\
Remote Australia & $639(0.5 \%)$ & $82(0.2 \%)$ & \\
$\quad$ Very remote Australia & $126(0.01 \%)$ & $12(0.04 \%)$ & \\
\hline
\end{tabular}

Table 3 Ordinal logistic regressions examining differences between people born in English speaking countries on activities of daily living, behavioural care needs and complex care needs compared to those born in non-English speaking countries after controlling for age, gender, remoteness and facility size

\begin{tabular}{llll}
\hline Variable & Beta & SE Beta & $\mathbf{p}$ \\
\hline Activities of daily living & & & \\
\hline Non-English vs non English & -.175 & .012 & $<0.001$ \\
speaking country & & & \\
Age & .006 & .001 & $<0.001$ \\
Sex & .188 & .010 & $<0.001$ \\
Remoteness & -.147 & .007 & $<0.001$ \\
Facility size & .003 & .000 & $<0.001$ \\
& & & \\
\hline Behavioural care needs & & & $<0.001$ \\
\hline Non-English vs non English & -.417 & .013 & \\
speaking country & & & $<0.001$ \\
Age & -.022 & .001 & \\
Sex & .078 & .011 &
\end{tabular}

This article is protected by copyright. All rights reserved 


$\begin{array}{llll}\text { Remoteness } & -.261 & .007 & <0.001 \\ \text { Facility size } & .001 & .000 & <0.001\end{array}$

\begin{tabular}{llll}
\hline \multicolumn{2}{l}{ Complex care needs } & & \\
\hline Non-English vs non English & -.125 & .012 & $<0.001$ \\
speaking country & & & \\
Age & .005 & .001 & $<0.001$ \\
Sex & .143 & .010 & $<0.001$ \\
Remoteness & -.234 & .007 & $<0.001$ \\
Facility size & .003 & .000 & $<0.001$ \\
\hline
\end{tabular}

Table 4. Number of facilities ethno-specific facilities for top 10 countries of birth

\begin{tabular}{lr}
\hline Country & $\begin{array}{r}\text { \# ethno-specific } \\
\text { facilities }\end{array}$ \\
\hline Italy & 11 \\
Germany & 0 \\
Greece & 9 \\
Netherlands & 4 \\
Poland & 3 \\
China (excludes SARs & 10 \\
and Taiwan) & 0 \\
India & 1 \\
Croatia & 0 \\
Malta & 1 \\
Hungary
\end{tabular}

This article is protected by copyright. All rights reserved 


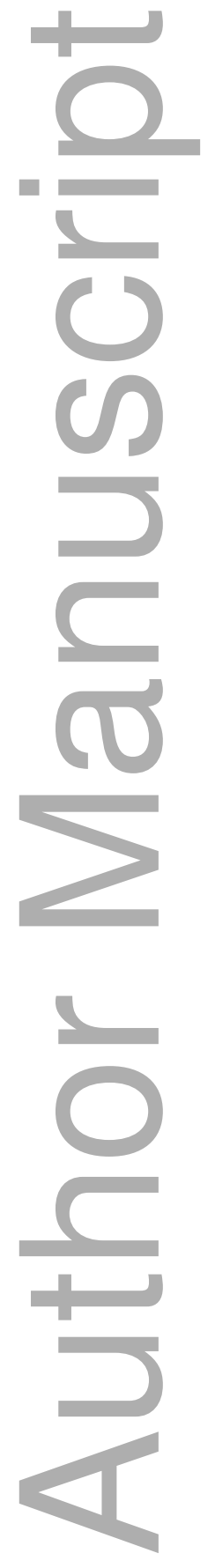

This article is protected by copyright. All rights reserved 
Table 5 Differences on care needs between residents born in non-English speaking countries living in multicultural facilities or ethnospecific facilities, and born in English-speaking countries living in non-multicultural or ethnospecific facilities

\begin{tabular}{|c|c|c|c|c|c|c|}
\hline 0 & $\begin{array}{l}\text { Non-English speaking } \\
\text { country of birth living } \\
\text { in multicultural } \\
\text { facility }(n=108 \text { ) }\end{array}$ & $\begin{array}{l}\text { English-speaking } \\
\text { country of birth living } \\
\text { in non-multicultural } \\
\text { facility ( } n=2571 \text { ) }\end{array}$ & Statistics & $\begin{array}{l}\text { Born in dominant } \\
\text { country of birth of } \\
\text { ethno-specific } \\
\text { facility they are } \\
\text { living in ( } n=39 \text { ) }\end{array}$ & $\begin{array}{l}\text { English-speaking } \\
\text { country of birth } \\
\text { living in non- } \\
\text { Ethno-specific } \\
\text { facility ( } n=2640 \text { ) }\end{array}$ & Statistics \\
\hline $\begin{array}{l}\text { Number of } \\
\text { residents }\end{array}$ & 7485 & 136095 & & 2000 & 136095 & \\
\hline $\begin{array}{l}\text { Activities of } \\
\text { daily living }\end{array}$ & & & $\begin{array}{l}x^{2}= \\
33.851 p<\end{array}$ & & & $\begin{array}{l}x^{2}= \\
15.386, p\end{array}$ \\
\hline Nil & 78 (1.0\%) & $1408(1.0 \%)$ & 0.001 & $20(1.0 \%)$ & $1408(1.0 \%)$ & $<0.001$ \\
\hline Low & 1234 (14.9\%) & 24383 (17.9\%) & & 297 (14.9\%) & $24383(17.9 \%)$ & \\
\hline Medium & 2165 (30.5\%) & 42086 (30.9\%) & & $610(30.5 \%)$ & $42086(30.9 \%)$ & \\
\hline High & 4008 (53.7\%) & $68218(50.1 \%)$ & & $1073(53.7 \%)$ & 68218 (50.1\%) & \\
\hline $\begin{array}{l}\text { Behavioural } \\
\text { care needs }\end{array}$ & & & $\begin{array}{l}x^{2}= \\
362.557\end{array}$ & & & $\begin{array}{l}x^{2}= \\
130.715\end{array}$ \\
\hline Nil & $45(2.5 \%)$ & $8425(6.2 \%)$ & $p<0.001$ & $45(2.2 \%)$ & 8425 (6.2\%) & $p<0.001$ \\
\hline Low & $176(9.2 \%)$ & 18487 (13.6\%) & & $176(8.8 \%)$ & $18487(13.6 \%)$ & \\
\hline Medium & $415(22.3 \%)$ & $31496(23.1 \%)$ & & 415 (20.8\%) & 31496 (23.1\%) & \\
\hline High & $1364(66.0 \%)$ & 77687 (57.1\%) & & $1364(68.2 \%)$ & 77687 (57.1\%) & \\
\hline
\end{tabular}




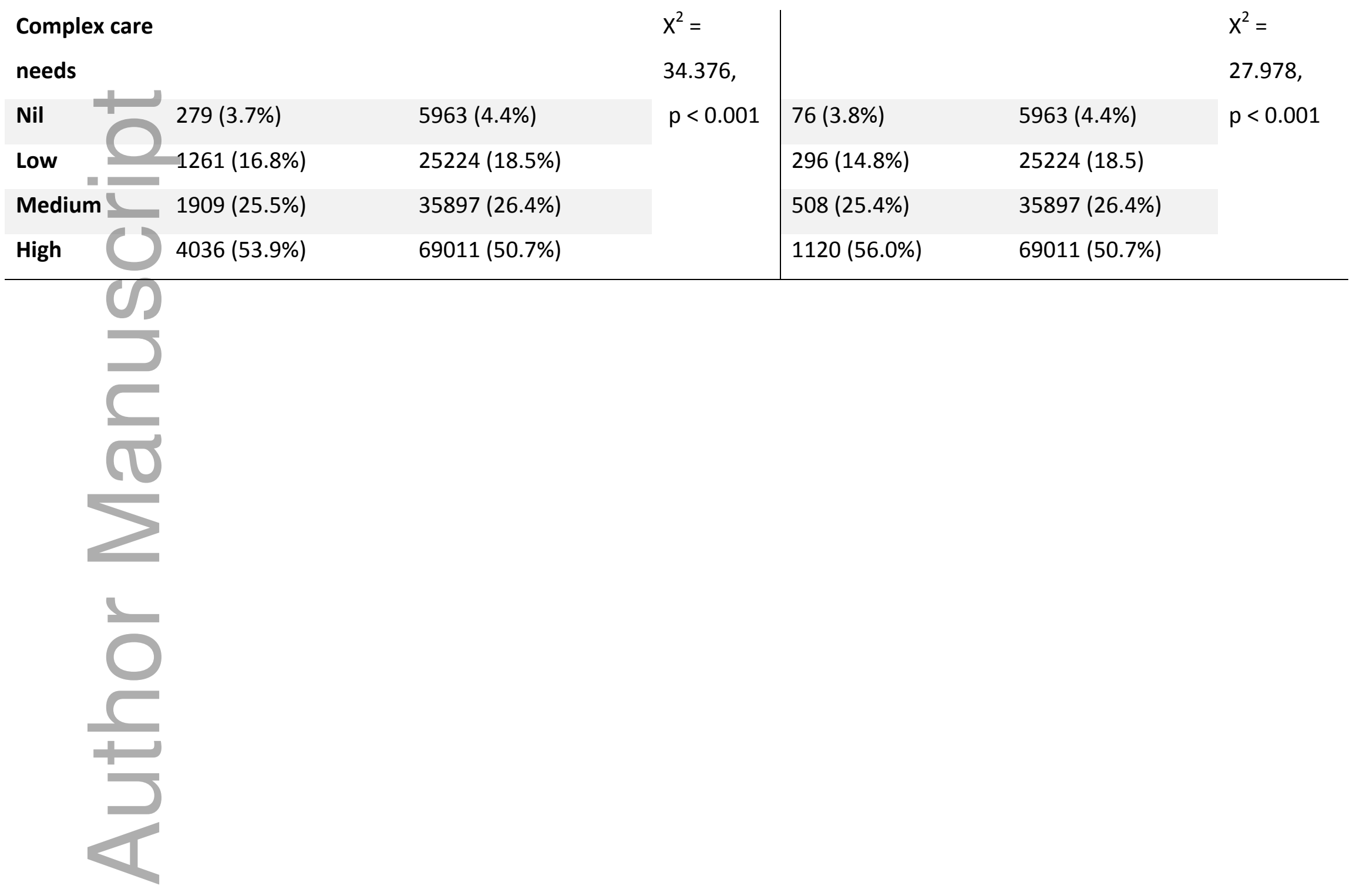

This article is protected by copyright. All rights reserved 


\section{University Library}

\section{- M M N E R VA A gateway to Melbourne's research publications}

Minerva Access is the Institutional Repository of The University of Melbourne

Author/s:

Low, L-F;LoGiudice, D

Title:

Residents from non-English-speaking countries of birth in Australian aged care facilities

Date:

2018-09-01

Citation:

Low, L. -F. \& LoGiudice, D. (2018). Residents from non-English-speaking countries of birth in Australian aged care facilities. AUSTRALASIAN JOURNAL ON AGEING, 37 (3), pp.E85-E90. https://doi.org/10.1111/ajag. 12527.

Persistent Link:

http://hdl.handle.net/11343/283910 